\title{
Analgesic Use and the Risk of Hearing Loss in Men
}

\author{
Sharon G. Curhan, MD, ScM ${ }^{1}$, Roland Eavey, MD ${ }^{2}$, Josef Shargorodsky, MD ${ }^{1,3}$, and Gary C. \\ Curhan, MD, ScD ${ }^{1,4}$ \\ ${ }^{1}$ Channing Laboratory, Department of Medicine, Brigham and Women's Hospital, Boston, MA \\ 2 Department of Otolaryngology, Vanderbilt University, Nashville, TN \\ ${ }^{3}$ Massachusetts Eye and Ear Infirmary, Boston, MA \\ ${ }^{4}$ Department of Epidemiology, Harvard School of Public Health, Boston, MA
}

\section{Abstract}

Background-Hearing loss is a common sensory disorder, yet prospective data on potentially modifiable risk factors are limited. Regularly used analgesics, the most commonly used drugs in the US, may be ototoxic and contribute to hearing loss.

Methods-We examined the independent association between self-reported professionally diagnosed hearing loss and regular use of aspirin, nonsteroidal anti-inflammatory drugs (NSAIDs), and acetaminophen in 26,917 men aged 40-74 years at baseline in 1986. Study participants completed detailed questionnaires at baseline and every two years thereafter. Incident cases of new onset hearing loss were defined as those diagnosed after 1986. Cox proportional hazards multivariate regression was used to adjust for potential confounding factors.

Results-During 369,079 person-years of follow-up, 3488 incident cases of hearing loss were reported. Regular use of each analgesic was independently associated with an increased risk of hearing loss. Multivariate-adjusted hazard ratios of hearing loss in regular users (2+ times/week) compared with men who used the specified analgesic <2 times/week were 1.12 (95\% CI, 1.04-1.20) for aspirin, 1.21 (95\% CI, 1.11-1.33) for NSAIDs, and 1.22 (95\% CI, 1.07-1.39) for acetaminophen. For NSAIDs and acetaminophen, the risk increased with longer duration of regular use. The magnitude of the association was substantially higher in younger men. For men younger than age 50, the hazard ratio for hearing loss was 1.33 for regular aspirin use, 1.61 for NSAIDs, and 1.99 for acetaminophen.

Conclusions-Regular use of aspirin, NSAIDs, or acetaminophen increases the risk of hearing loss in men and the impact is larger on younger individuals.

\section{Keywords}

hearing loss; analgesics; prospective study

Corresponding author: Sharon G. Curhan, MD, ScM, Channing Laboratory, Brigham and Women's Hospital, 181 Longwood Avenue, Boston, MA 02115, Tel: 617-525-2028, Fax: 617-525-2008, scurhan@ partners.org.

All authors had access to the data and a role in writing the manuscript.

Publisher's Disclaimer: This is a PDF file of an unedited manuscript that has been accepted for publication. As a service to our customers we are providing this early version of the manuscript. The manuscript will undergo copyediting, typesetting, and review of the resulting proof before it is published in its final citable form. Please note that during the production process errors may be discovered which could affect the content, and all legal disclaimers that apply to the journal pertain. 


\section{Background}

Hearing loss is the most common sensory disorder in the US and afflicts over 36 million people.

${ }^{1}$ Data from the National Health and Nutrition Examination Survey (NHANES) demonstrate that not only is hearing loss highly prevalent among the elderly, but approximately one-third of those aged 40-49 already suffer from hearing loss. ${ }^{2}$ The 5-year incidence of developing hearing loss in adults aged 48 years and older is $21 \% .3$ Even mild hearing loss can compromise the ability to understand speech in the presence of background noise or multiple speakers, leading to social isolation, depression, and poorer quality of life. $4^{-7}$

Aspirin, acetaminophen and ibuprofen are the three most commonly used drugs in the U.S.8 While $17 \%$ of the total population uses aspirin at least weekly, over $28 \%$ of men aged 45 and above are aspirin users. Similarly, acetaminophen is used at least weekly by $23 \%$ of the population and ibuprofen is used by $17 \% .8$ The ototoxic effects of high doses (several grams per day) of salicylates, reversible hearing loss and tinnitus, are well documented. ${ }^{9}$ High doses of nonsteroidal anti-inflammatory drugs (NSAIDs) have been shown to be ototoxic in animals and in human case reports, 15 potentially through a reduction in cochlear blood flow.9 Preexposure to salicylates and NSAIDs may potentiate noise-induced hearing loss.10, 11 Acetaminophen may deplete glutathione, ${ }^{16}$ which has been shown to protect the cochlea from noise-induced damage. ${ }^{17,} 18$ The relation between acetaminophen and hearing loss has not been studied.

Given that analgesic use may result in pathophysiologic changes in the cochlea and that regular use of these analgesics is so common, the relation of these medications and hearing loss may be an important public health issue. Therefore, we prospectively examined the association between regular analgesic use and risk of hearing loss in over 26,000 men.

\section{Methods}

Participants

The Health Professionals Follow-up Study originally enrolled 51,529 male dentists, optometrists, osteopaths, pharmacists, podiatrists, and veterinarians who were 40-75 years of age at baseline in 1986. Study participants filled out detailed questionnaires about diet, medical history, and medication use. These questionnaires have been administered every other year, and the 20-year follow-up exceeds $90 \%$. The 2004 long form questionnaire included a question regarding whether the participant had been professionally diagnosed with hearing loss, and if so, the date of diagnosis. Of the 31,496 men who returned the long form questionnaire, 8291 $(26.3 \%)$ reported a diagnosis of hearing loss. Those who reported hearing loss diagnosed before $1986(n=2845)$ or cancer other than non-melanoma skin cancer (due to possible exposure to ototoxic chemotherapeutic agents), were excluded from the analysis. Recent data from NHANES demonstrate that $43 \%$ of white men aged 60-69 exhibit low-mid frequency hearing loss and $93 \%$ exhibit high-frequency hearing loss. ${ }^{2}$ Thus, because age is such a strong risk factor and the prevalence of hearing loss is so high among the elderly, we also excluded men as they reached age 75 during follow-up. The number of men included in the analysis was 26,917 .

\section{Ascertainment of Analgesic Use}

On the 1986 questionnaire and every 2 years thereafter, men were asked about regular use, defined as two or more times per week, of aspirin, NSAIDs and acetaminophen. Our primary analyses examined regular analgesic use. If information on analgesic intake was missing for a time period, person-time for that participant was not included for that time period. Analgesic 
use assessed in this manner has been shown to be associated with a number of important outcomes in this cohort, such as colorectal cancer ${ }^{19}$ and hypertension. ${ }^{20}$

\section{Ascertainment of Outcome}

The primary outcome, self-reported professionally diagnosed hearing loss, was determined based on the response to a hearing loss question on the 2004 long form questionnaire. The question asked whether the participant had ever had professionally diagnosed hearing loss and the year of first diagnosis.

We defined incident cases as hearing loss diagnosed after 1986. Although standard pure-tone audiometry is generally considered the gold standard of hearing loss evaluation, due to the cost and logistic limitations of audiometric screening, several survey instruments have been developed to evaluate large populations. Studies that have compared the reliability of selfreport to the gold standard of audiometry $21^{-} 24$ demonstrate that self-reported hearing loss is a reasonably reliable measure of hearing loss. ${ }^{21}$ For example, based on NHANES data using the definition of hearing loss to be a pure-tone average (at 500, 1000, 2000 and $4000 \mathrm{kHz}$ ) $25 \mathrm{~dB}$ in both ears, the sensitivity was $65 \%$ and the specificity was $83 \%$ in a comparison of self-report to audiometry. ${ }^{2}$

\section{Ascertainment of Covariates}

We selected covariates that have been purported to be risk factors for hearing loss. Covariates considered in the multivariate analysis included: age, 2 race, ${ }^{2}$ body mass index (BMI), ${ }^{25}$ alcohol intake, 26 folate intake, 27 physical activity, 28 smoking, ${ }^{26}$ hypertension, diabetes,${ }^{29}$ cardiovascular disease, ${ }^{30}$ elevated cholesterol, ${ }^{30}$ and use of furosemide. ${ }^{31}$

Age and race were obtained from biennial questionnaires. Height and weight were obtained from the baseline questionnaire with self-reported weight updated every two years. Body mass index (BMI) was calculated as weight in kilograms divided by the square of height in meters. Information on smoking status and physical activity was updated every two years. Intakes of alcohol and folate were calculated from semiquantitative food frequency questionnaires that were mailed to participants every four years. Information on other covariates was available from the biennial questionnaires, including diagnoses of hypertension, diabetes mellitus, cardiovascular disease, elevated cholesterol, and use of furosemide.

Questionnaire derived information has been validated for many of the covariates by comparison with directly measured values or detailed diaries, with correlations of 0.97 for weight, ${ }^{32} 0.79$ for physical activity ${ }^{33}$ and 0.9 for alcohol intake. ${ }^{34}$

\section{Statistical Analysis}

All analyses were prospective, using information on analgesic use that was collected prior to the diagnosis of hearing loss. For the primary analyses, the frequency of use of a particular analgesic was categorized as regular users ( 2 or more times per week) or non-regular users (less than twice per week). For each participant, person-time was allocated based on the response to the analgesic questions at the beginning of each follow-up period. Participants were censored at the date of diagnosis of hearing loss or cancer, age 75, or the date of death, whichever came first. Age- and multivariable-adjusted hazard ratios (HRs) were calculated using Cox proportional hazards regression models. Multivariable models were adjusted for potential confounders listed above as well as simultaneously for use of the other analgesic types.

To examine whether the relation between regular analgesic use and hearing loss varied by age, we performed analyses stratified by age $<50$ years, $50-59$, and 60 and older. 
Secondary analyses examined the association between duration of regular analgesic use and hearing loss. Duration of regular aspirin use was categorized according to years of regular use $(0,1-4,5-8,>8)$. For NSAIDs and acetaminophen, duration of regular use was categorized similarly, however the highest categories were collapsed into a category of $>4$ years of regular use as too few cases were in the categories of longer duration. We also examined whether the relation between hearing loss and regular analgesic use varied with concomitant regular use of more than one class of analgesic. Analgesic use was categorized as regular use of all 3 classes of analgesics, regular use of aspirin and NSAIDs only, NSAIDs and acetaminophen only, aspirin and acetaminophen only, aspirin only, NSAIDs only, acetaminophen only, or no regular analgesic use.

For all HRs, we calculated 95\% confidence intervals (CIs). All $P$ values are two-tailed. Statistical tests were performed using SAS statistical software, version 9 (SAS Institute Inc, Cary, NC).

\section{Role of the funding source}

The sponsors of the study had no role in study design, data collection, data analysis, data interpretation, or writing of the report. The corresponding author had full access to all the data in the study and had final responsibility for the decision to submit for publication.

\section{Results}

Characteristics of participants at baseline according to analgesic use are shown in Table 1. Although updated information was used for the analysis, characteristics are presented from baseline to provide representative values. Regular aspirin and NSAID users were older and acetaminophen users were younger than non-regular users. Hypertension was more common among regular analgesic users. It was common for an individual to use more than one type of analgesic regularly.

During 369,079 person-years of follow-up, 3488 cases of hearing loss were reported. Regular analgesic use was independently associated with an increased risk of hearing loss for all three types of analgesics (Table 2). After adjusting for age, race, profession, BMI, alcohol intake, folate intake, physical activity, smoking, hypertension, diabetes, and the use of the other classes of analgesics, the multivariate HRs of hearing loss in participants who were regular users compared with participants who used the specified analgesic less than twice per week were 1.12 (95\%CI, 1.04-1.20) for aspirin, 1.21 (95\% CI, 1.11-1.33) for NSAIDs, and 1.22 (95\% CI, 1.07-1.39) for acetaminophen. When further adjusted for history of elevated cholesterol, cardiovascular disease or use of furosemide, or after exclusion of individuals with rheumatoid arthritis or osteoarthritis, the results were materially unchanged.

For NSAIDs and acetaminophen, the risk of hearing loss increased with longer duration of regular use (Table 3). Those who used aspirin regularly for 1-4 years were 28\% (17-40\%) more likely to develop hearing loss than those who did not use aspirin regularly; the risk did not increase further with longer duration of use. Those who used NSAIDs regularly for four or more years were 33\% (18-49\%) more likely to develop hearing loss than those who did not use NSAIDs regularly. The risk of four or more years of regular acetaminophen use was also $33 \%(14-56 \%)$ higher.

The association between hearing loss and regular use of aspirin ( $\mathrm{p}$, interaction=0.005), NSAIDs $(\mathrm{p}$, interaction $=0.10)$, and acetaminophen $(\mathrm{p}$, interaction $=0.09)$ varied by age $($ Table 4$)$. For each class of analgesic, the magnitude of the association tended to decrease with advancing age. For aspirin, regular users aged less than 50 and those aged 50-59 were 33\% more likely to have hearing loss than were non-regular users, but there was no association among men aged 
60 and older. For NSAIDs, regular users aged less than 50 were $61 \%$ more likely, those aged 50-59 were 32\% more likely, and those aged 60 and older were $16 \%$ more likely to develop hearing loss than non-regular users of NSAIDs. For acetaminophen, regular users aged less than 50 were $99 \%$ more likely, regular users aged 50-59 were 38\% more likely, and those aged 60 and older were $16 \%$ more likely to have hearing loss than non-regular users of acetaminophen.

The association between hearing loss and concomitant use of more than one class of analgesic appeared to be approximately additive (Table 5). For the combined use of 2 analgesics, the risk was highest for use of NSAIDs and acetaminophen (HR=1.58 (1.16-2.16)), as compared to those who did not use any of the analgesics regularly. This risk was similar to the impact of regular use of all 3 analgesics ( $\mathrm{HR}=1.60(1.23-2.09))$.

\section{Discussion}

Regular analgesic use was independently associated with an increased risk of hearing loss. The increased risk of hearing loss seen with regular analgesic use was greatest among younger men, particularly those below age 60 . In men aged 60 and above, there was no relation observed between the risk of hearing loss and regular aspirin use, and the relation between regular use of NSAIDs and acetaminophen was attenuated. The risk of hearing loss increased with longer duration of analgesic use for both NSAIDs and acetaminophen.

The ototoxic effects of high dose salicylates, reversible hearing loss and tinnitus, are well documented. ${ }^{9}$ In animal models, salicylate administration results in abnormal outer hair cell function and decreased cochlear blood flow. ${ }^{9}$ Salicylates induce biochemical and electrophysiological changes that alter membrane conductance of outer hair cells ${ }^{35}$ and vasoconstriction in auditory microvasculature, possibly mediated by antiprostaglandin activity. 36

High doses of NSAIDs have also been reported to be ototoxic in animal studies and in human case reports. ${ }^{15}$ Similar to salicylates, NSAIDs inhibit cyclooxygenase and decrease prostaglandin activity, potentially reducing cochlear blood flow. ${ }^{9}$

Histopathologic studies of human temporal bones ${ }^{37}$ and in animals show degeneration of strial microvasculature. ${ }^{38}$ These studies suggest that vascular compromise, such as that which may result from salicylate or NSAID use, contributes to strial degeneration. Degeneration of the stria vascularis, a highly vascularized and metabolically active region of the cochlea, is a notable pathophysiologic change characteristic of age-related hearing $\operatorname{loss}^{39}$ that may reduce the endolymphatic potential and the function of the cochlear amplifier.

The relation between acetaminophen and hearing loss has not been studied previously. Frequent use of acetaminophen has been associated with hypertension ${ }^{20,40,41}$ and chronic renal dysfunction. ${ }^{42,43}$ Acetaminophen use increases risk of renal function decline, potentially due to depletion of glutathione. ${ }^{16}$ Acetaminophen may also deplete endogenous cochlear glutathione, which is present in the cochlea in substantial amounts and protects the cochlea from noise-induced damage. ${ }^{17,} 18$

The prevalence of hearing loss increases with age. ${ }^{44}$ After age 60 , hearing thresholds worsen on average by $1 \mathrm{~dB}$ per year ${ }^{45}$ and the rate of decline may be even greater in men aged 48-59 years. ${ }^{46}$ The magnitude of the relation between regular analgesic use and hearing loss was greatest in men younger than age 60. Possibly, the relative contribution of regular analgesic use to hearing loss may be greater in younger individuals before the cumulative effects of age and other factors have accrued. A similar impact of age on the relative contribution of diabetes to hearing loss was seen by Bainbridge et al. ${ }^{29}$ 
The risk of hearing loss increased with longer duration of regular use of NSAIDs and acetaminophen, but not of aspirin. However, years of use were counted from the 1986 baseline questionnaire when the mean age of participants was 51 years. Thus, those who reported 11 or more years of aspirin use were older. As the relation between analgesic use and hearing loss diminished with increasing age, this likely explains the lack of association between longer duration of aspirin use and hearing loss.

The impact of regular use of multiple analgesics appeared to be additive. This raises the possibility that the different classes of analgesics may impair auditory function through different mechanisms.

Our study has limitations. Assessment of hearing loss was based on self-report of professionally diagnosed hearing loss and individuals who did not report hearing loss were considered not to be hearing impaired. Although standard pure-tone audiometry is generally considered the gold standard of hearing loss evaluation, self-reported hearing loss has been demonstrated to be a reliable assessment. Moreover, participants were specifically queried as to whether they had been "professionally diagnosed" with hearing loss, a more objective measure than the frequently used single question, "Do you feel you have a hearing loss?" Nevertheless, given the high prevalence of hearing loss in men of this age group, ${ }^{2}$ there may have been misclassification of outcome.

We also did not have information on lifetime noise exposure or reasons for analgesic use. Noise is a common cause of hearing loss, and its targets overlap with those that may be compromised by analgesics. Moreover, noise exposure may increase the vulnerability to hearing loss related to age ${ }^{47-} 49$ or other causes.50 A study of patterns of medication use in the US found that $58 \%$ of older men reported cardiovascular prophylaxis was the most common reason for aspirin use. Other reasons for use of OTC medications, of which acetaminophen, ibuprofen, and aspirin were the most common, included headache and pain. $8 \mathrm{We}$ did not find any published reports relating common headache with hearing loss. Although migraine headaches may be associated with temporary hearing loss, ${ }^{51}$ the prevalence of migraine headaches in men in the US is low $(6 \%),{ }^{52}$ thus unlikely to explain our findings. Autoimmune diseases, such as rheumatoid arthritis, may cause hearing loss, 53 but these conditions are extremely rare in men and unlikely to have influenced our results. Hypertension may increase the risk of hearing loss due to changes in the cochlear microvasculature,54 as may cardiovascular disease, such as stroke, coronary heart disease and intermittent claudication, 30 however, we adjusted for these in our analyses and our results were not materially changed.

The present study was carried out in a population of predominantly white men, thus the results may not be generalizable to other racial groups. Although the participants in this cohort may not be representative of the adult population in the U.S., follow-up rates are high and information provided is reliable. The observed associations are likely to apply to other groups inasmuch as the underlying biologic and pharmacologic mechanisms are likely to be similar. However, additional studies are needed to examine these associations in women and younger men.

Regular use of analgesics, specifically aspirin, NSAIDs, and acetaminophen, may increase the risk of adult hearing loss, particularly in younger individuals. Given the high prevalence of regular analgesic use and health and social implications of hearing impairment, this represents an important public health issue.

\section{Acknowledgments}

This work was supported by NIH grant P01 CA055075 and MEEI Foundation. 


\section{References}

1. Pleis JR, Lethbridge-Cejku M. Summary health statistics for U.S. adults: National Health Interview Survey, 2006. Vital Health Stat Dec;2007 10(235):1-153.

2. Agrawal Y, Platz EA, Niparko JK. Prevalence of hearing loss and differences by demographic characteristics among US adults: data from the National Health and Nutrition Examination Survey, 1999-2004. Arch Intern Med Jul 28;2008 168(14):1522-1530. [PubMed: 18663164]

3. Cruickshanks KJ, Tweed TS, Wiley TL, et al. The 5-year incidence and progression of hearing loss: the epidemiology of hearing loss study. Arch Otolaryngol Head Neck Surg Oct;2003 129(10):10411046. [PubMed: 14568784]

4. Gates GA, Mills JH. Presbycusis. Lancet Sep 24-30;2005 366(9491):1111-1120. [PubMed: 16182900]

5. Dalton DS, Cruickshanks KJ, Klein BE, Klein R, Wiley TL, Nondahl DM. The impact of hearing loss on quality of life in older adults. Gerontologist Oct;2003 43(5):661-668. [PubMed: 14570962]

6. Uhlmann RF, Larson EB, Rees TS, Koepsell TD, Duckert LG. Relationship of hearing impairment to dementia and cognitive dysfunction in older adults. JAMA Apr 7;1989 261(13):1916-1919. [PubMed: 2926927]

7. Gates GA, Cobb JL, Linn RT, Rees T, Wolf PA, D'Agostino RB. Central auditory dysfunction, cognitive dysfunction, and dementia in older people. Arch Otolaryngol Head Neck Surg Feb;1996 122 (2):161-167. [PubMed: 8630210]

8. Kaufman DW, Kelly JP, Rosenberg L, Anderson TE, Mitchell AA. Recent patterns of medication use in the ambulatory adult population of the United States: the Slone survey. JAMA Jan 16;2002 287(3): 337-344. [PubMed: 11790213]

9. Jung TT, Rhee CK, Lee CS, Park YS, Choi DC. Ototoxicity of salicylate, nonsteroidal antiinflammatory drugs, and quinine. Otolaryngol Clin North Am Oct;1993 26(5):791-810. [PubMed: 8233489]

10. McFadden D, Plattsmier HS. Aspirin can potentiate the temporary hearing loss induced by intense sounds. Hear Res Mar;1983 9(3):295-316. [PubMed: 6841285]

11. McFadden D, Plattsmier HS, Pasanen EG. Temporary hearing loss induced by combinations of intense sounds and nonsteroidal anti-inflammatory drugs. Am J Otolaryngol Jul-Aug;1984 5(4):235-241. [PubMed: 6486350]

12. Chen Y, Huang WG, Zha DJ, et al. Aspirin attenuates gentamicin ototoxicity: from the laboratory to the clinic. Hear Res Apr;2007 226(1-2):178-182. [PubMed: 16844331]

13. Kopke RD, Weisskopf PA, Boone JL, et al. Reduction of noise-induced hearing loss using L-NAC and salicylate in the chinchilla. Hear Res Nov;2000 149(1-2):138-146. [PubMed: 11033253]

14. Huang ZW, Luo Y, Wu Z, Tao Z, Jones RO, Zhao HB. Paradoxical enhancement of active cochlear mechanics in long-term administration of salicylate. J Neurophysiol Apr;2005 93(4):2053-2061. [PubMed: 15590729]

15. McKinnon BJ, Lassen LF. Naproxen-associated sudden sensorineural hearing loss. Mil Med Nov; 1998 163(11):792-793. [PubMed: 9819544]

16. Moldeus P, Rahimtula A. Metabolism of paracetamol to a glutathione conjugate catalyzed by prostaglandin synthetase. Biochem Biophys Res Commun Sep 16;1980 96(1):469-475. [PubMed: 6776953]

17. Yamasoba T, Harris C, Shoji F, Lee RJ, Nuttall AL, Miller JM. Influence of intense sound exposure on glutathione synthesis in the cochlea. Brain Res Aug 31;1998 804(1):72-78. [PubMed: 9729286]

18. Yamasoba T, Nuttall AL, Harris C, Raphael Y, Miller JM. Role of glutathione in protection against noise-induced hearing loss. Brain Res Feb 16;1998 784(1-2):82-90. [PubMed: 9518561]

19. Chan AT, Ogino S, Fuchs CS. Aspirin and the risk of colorectal cancer in relation to the expression of COX-2. N Engl J Med May 24;2007 356(21):2131-2142. [PubMed: 17522398]

20. Forman JP, Rimm EB, Curhan GC. Frequency of analgesic use and risk of hypertension among men. Arch Intern Med Feb 26;2007 167(4):394-399. [PubMed: 17325302]

21. Sindhusake D, Mitchell P, Smith W, et al. Validation of self-reported hearing loss. The Blue Mountains Hearing Study. Int J Epidemiol Dec;2001 30(6):1371-1378. [PubMed: 11821349]

22. Nondahl DM, Cruickshanks KJ, Wiley TL, Tweed TS, Klein R, Klein BE. Accuracy of self-reported hearing loss. Audiology Sep-Oct;1998 37(5):295-301. [PubMed: 9776206] 
23. Valete-Rosalino CM, Rozenfeld S. Auditory screening in the elderly: comparison between self-report and audiometry. Braz J Otorhinolaryngol Mar-Apr;2005 71(2):193-200. [PubMed: 16446917]

24. Gates GA, Cooper JC Jr, Kannel WB, Miller NJ. Hearing in the elderly: the Framingham cohort, 1983-1985. Part I. Basic audiometric test results. Ear Hear Aug;1990 11(4):247-256. [PubMed: 2210098]

25. Seidman MD. Effects of dietary restriction and antioxidants on presbyacusis. Laryngoscope May; 2000 110(5 Pt 1):727-738. [PubMed: 10807352]

26. Itoh A, Nakashima T, Arao H, et al. Smoking and drinking habits as risk factors for hearing loss in the elderly: epidemiological study of subjects undergoing routine health checks in Aichi, Japan. Public Health May;2001 115(3):192-196. [PubMed: 11429714]

27. Durga J, Verhoef P, Anteunis LJ, Schouten E, Kok FJ. Effects of folic acid supplementation on hearing in older adults: a randomized, controlled trial. Ann Intern Med Jan 2;2007 146(1):1-9. [PubMed: 17200216]

28. Li Y, Healy EW, Drane JW, Zhang J. Comorbidity between and risk factors for severe hearing and memory impairment in older Americans. Prev Med Nov;2006 43(5):416-421. [PubMed: 16876854]

29. Bainbridge KE, Hoffman HJ, Cowie CC. Diabetes and hearing impairment in the United States: audiometric evidence from the National Health and Nutrition Examination Survey, 1999 to 2004. Ann Intern Med Jul 1;2008 149(1):1-10. [PubMed: 18559825]

30. Gates GA, Cobb JL, D'Agostino RB, Wolf PA. The relation of hearing in the elderly to the presence of cardiovascular disease and cardiovascular risk factors. Arch Otolaryngol Head Neck Surg Feb; 1993 119(2):156-161. [PubMed: 8427676]

31. Rybak LP, Whitworth C, Scott V. Comparative acute ototoxicity of loop diuretic compounds. Eur Arch Otorhinolaryngol 1991;248(6):353-357. [PubMed: 1930985]

32. Rimm EB, Stampfer MJ, Colditz GA, Chute CG, Litin LB, Willett WC. Validity of self-reported waist and hip circumferences in men and women. Epidemiology Nov;1990 1(6):466-473. [PubMed: 2090285]

33. Chasan-Taber S, Rimm EB, Stampfer MJ, et al. Reproducibility and validity of a self-administered physical activity questionnaire for male health professionals. Epidemiology Jan;1996 7(1):81-86. [PubMed: 8664406]

34. Willett, WC. Nutritional Epidemiology. 2. New York: Oxford University Press; 1998.

35. Stypulkowski PH. Mechanisms of salicylate ototoxicity. Hear Res Jun;1990 46(1-2):113-145. [PubMed: 2380120]

36. Brien JA. Ototoxicity associated with salicylates. A brief review. Drug Saf Aug;1993 9(2):143-148. [PubMed: 8397891]

37. Nelson EG, Hinojosa R. Presbycusis: a human temporal bone study of individuals with downward sloping audiometric patterns of hearing loss and review of the literature. Laryngoscope Sep;2006 116(9 Pt 3 Suppl 112):1-12. [PubMed: 16946668]

38. Gratton MA, Schulte BA. Alterations in microvasculature are associated with atrophy of the stria vascularis in quiet-aged gerbils. Hear Res Jan;1995 82(1):44-52. [PubMed: 7744712]

39. Spicer SS, Schulte BA. Spiral ligament pathology in quiet-aged gerbils. Hear Res Oct;2002 172(12):172-185. [PubMed: 12361880]

40. Forman JP, Stampfer MJ, Curhan GC. Non-narcotic analgesic dose and risk of incident hypertension in US women. Hypertension Sep;2005 46(3):500-507. [PubMed: 16103274]

41. Curhan GC, Willett WC, Rosner B, Stampfer MJ. Frequency of analgesic use and risk of hypertension in younger women. Arch Intern Med Oct 28;2002 162(19):2204-2208. [PubMed: 12390063]

42. Fored CM, Ejerblad E, Lindblad P, et al. Acetaminophen, aspirin, and chronic renal failure. N Engl J Med Dec 20;2001 345(25):1801-1808. [PubMed: 11752356]

43. Curhan GC, Knight EL, Rosner B, Hankinson SE, Stampfer MJ. Lifetime nonnarcotic analgesic use and decline in renal function in women. Arch Intern Med Jul 26;2004 164(14):1519-1524. [PubMed: 15277282]

44. Cruickshanks KJ, Wiley TL, Tweed TS, et al. Prevalence of hearing loss in older adults in Beaver Dam, Wisconsin. The Epidemiology of Hearing Loss Study. Am J Epidemiol Nov 1;1998 148(9): 879-886. [PubMed: 9801018] 
45. Lee FS, Matthews LJ, Dubno JR, Mills JH. Longitudinal study of pure-tone thresholds in older persons. Ear Hear Feb;2005 26(1):1-11. [PubMed: 15692300]

46. Wiley TL, Chappell R, Carmichael L, Nondahl DM, Cruickshanks KJ. Changes in hearing thresholds over 10 years in older adults. J Am Acad Audiol Apr;2008 19(4):281-292. quiz 371. [PubMed: 18795468]

47. Gates GA, Schmid P, Kujawa SG, Nam B, D'Agostino R. Longitudinal threshold changes in older men with audiometric notches. Hear Res Mar;2000 141(1-2):220-228. [PubMed: 10713509]

48. Kujawa SG, Liberman MC. Acceleration of age-related hearing loss by early noise exposure: evidence of a misspent youth. J Neurosci Feb 15;2006 26(7):2115-2123. [PubMed: 16481444]

49. Erway LC, Shiau YW, Davis RR, Krieg EF. Genetics of age-related hearing loss in mice. III. Susceptibility of inbred and F1 hybrid strains to noise-induced hearing loss. Hear Res Apr;1996 93 (1-2):181-187. [PubMed: 8735078]

50. Brown RD, Penny JE, Henley CM, et al. Ototoxic drugs and noise. Ciba Found Symp 1981;85:151171. [PubMed: 7035098]

51. Dash AK, Panda N, Khandelwal G, Lal V, Mann SS. Migraine and audiovestibular dysfunction: is there a correlation? Am J Otolaryngol Sep-Oct;2008 29(5):295-299. [PubMed: 18722884]

52. Lipton RB, Bigal ME. The epidemiology of migraine. Am J Med Mar;2005 118( Suppl 1):3S-10S. [PubMed: 15841882]

53. Ozturk A, Yalcin S, Kaygusuz I, et al. High-frequency hearing loss and middle ear involvement in rheumatoid arthritis. Am J Otolaryngol Nov-Dec;2004 25(6):411-417. [PubMed: 15547810]

54. Brant LJ, Gordon-Salant S, Pearson JD, et al. Risk factors related to age-associated hearing loss in the speech frequencies. J Am Acad Audiol Jun;1996 7(3):152-160. [PubMed: 8780987] 


\section{Table 2}

Age- and Multivariate-Adjusted Hazard Ratios for Analgesic Use and Incident Hearing loss

\begin{tabular}{lcccc}
\hline $\begin{array}{l}\text { Analgesic Medication } \\
\text { Aspirin }\end{array}$ & Cases & Person-years & Age-adjusted Hazard Ratio & Multivariate Hazard Ratio* \\
$<2$ per week & 1769 & 213831 & 1.0 & 1.0 \\
$\begin{array}{l}2+\text { per week } \\
\text { NSAIDs }\end{array}$ & 1711 & 154412 & $1.13(1.06-1.21)$ & $1.12(1.04-1.20)$ \\
$<2$ per week & 2852 & 320467 & 1.0 & 1.0 \\
$2+$ per week & 636 & 48612 & $1.38(1.27-1.50)$ & $1.21(1.11-1.33)$ \\
Acetaminophen & & & & 1.0 \\
$<2$ per week & 3214 & 347362 & 1.0 & $1.22(1.07-1.39)$ \\
$2+$ per week & 274 & 21717 & $1.32(1.17-1.50)$ & \\
\hline
\end{tabular}

*Adjusted for age, BMI, alcohol, physical activity, folate, smoking, hypertension, diabetes, profession, race, as well as the other analgesics 


\section{Table 3}

Age and Multivariate Adjusted Hazard Ratios for Hearing loss According to Duration of Analgesic Intake

\begin{tabular}{lrrcc}
\hline $\begin{array}{l}\text { Duration of use } \\
\text { (years) }\end{array}$ & Cases & Person-years & Age-adjusted Hazard Ratio & Multivariate Hazard Ratio* \\
Aspirin & & & & \\
0 & 1042 & 156188 & 1.0 & 1.0 \\
$1-4$ & 1122 & 108177 & $1.35(1.24-1.46)$ & $1.28(1.17-1.40)$ \\
$5-8$ & 687 & 56431 & $1.34(1.22-1.48)$ & $1.30(1.17-1.44)$ \\
$>8$ & 637 & 48282 & $1.26(1.14-1.40)$ & $1.17(1.04-1.31)$ \\
NSAIDs & & & & $1.23(1.12-1.34)$ \\
0 & 2409 & 284706 & 1.0 & $1.33(1.18-1.49)$ \\
$1-4$ & 721 & 59774 & $1.30(1.20-1.42)$ & \\
$>4$ & 358 & 24600 & $1.41(1.26-1.57)$ & 1.0 \\
Acetaminophen & & & & $1.19(1.07-1.32)$ \\
0 & 2897 & 320893 & 1.0 & $1.33(1.14-1.56)$ \\
$1-4$ & 420 & 36348 & $1.23(1.11-1.36)$ & \\
$>4$ & 171 & 11838 & $1.39(1.19-1.62)$ & \\
\hline
\end{tabular}

*Adjusted for age, BMI, alcohol, physical activity, folate, smoking, hypertension, diabetes, profession, race, as well as the other analgesics 


\section{Table 4}

Analgesic Use and the Age-Adjusted and Multivariate* Hazard Ratios for Incident Hearing Loss Stratified by Age

\begin{tabular}{lccc}
\hline Analgesic & Age $<\mathbf{5 0} \mathbf{~ y r}$ & Age 50-59 yr & Age 60+ yr \\
Aspirin (age-adj) & $1.32(1.02-1.69)$ & $1.36(1.20-1.54)$ & $1.03(0.94-1.12)$ \\
$\quad$ (multivar) & $1.33(1.03-1.72)$ & $1.33(1.17-1.50)$ & $1.02(0.93-1.11)$ \\
NSAIDs (age-adj) & $1.59(1.14-2.23)$ & $1.35(1.15-1.58)$ & $1.17(1.04-1.31)$ \\
$\quad$ (multivar) & $1.61(1.15-2.26)$ & $1.32(1.13-1.55)$ & $1.16(1.03-1.30)$ \\
Acetaminophen (age) & $1.91(1.29-2.82)$ & $1.37(1.09-1.73)$ & $1.17(0.99-1.37)$ \\
$\quad$ (multivar) & $1.99(1.34-2.95)$ & $1.38(1.09-1.74)$ & $1.16(0.99-1.37)$ \\
\hline
\end{tabular}

* Adjusted for age, BMI, alcohol, physical activity, folate, smoking, hypertension, diabetes, profession, race, as well as the other analgesics 
Table 5

Age- and Multivariate-Adjusted Hazard Ratios for Concommitant Regular Use of More Than One Type of Analgesic and Incident Hearing loss

\begin{tabular}{lrrcc}
\hline Analgesic & Cases & Person-years & Age-adjusted Hazard Ratio & Multivariate Hazard Ratio $^{*}$ \\
None & 1378 & 182,380 & 1.0 & 1.0 \\
All 3 Analgesics & 60 & 3809 & $1.75(1.35-2.26)$ & $1.60(1.23-2.09)$ \\
NSAIDs + Acetaminophen & 43 & 3015 & $1.72(1.27-2.32)$ & $1.58(1.16-2.16)$ \\
Aspirin + Acetaminophen & 97 & 7769 & $1.44(1.17-1.76)$ & $1.40(1.13-1.73)$ \\
Aspirin + NSAIDs & 250 & 19,832 & $1.37(1.20-1.57)$ & $1.25(1.09-1.44)$ \\
\hline
\end{tabular}

* Adjusted for age, BMI, alcohol, physical activity, folate, smoking, hypertension, diabetes, profession, race and all categories of analgesic use 